\section{A case of the $G$ syndrome}

Published cases of the G syndrome (hypertelorism, hypospadias, and laryngotracheo-oesophageal abnormality) number less than $30 .^{1}$ This report describes a male infant with severe and unusual manifestations of this disorder.

Birth weight at term was $4.3 \mathrm{~kg}$. The pregnancy was marked by brief vaginal spotting at 4 months and polyhydramnios. The child was fully assessed aged 10 days because of multiple congenital abnormalities, cardiac failure, and feeding difficulties. Examination revealed (figure) hypertelorism (inner canthal distance $3.0 \mathrm{~cm}$, interpupillary distance $5.5 \mathrm{~cm}$, outer canthal distance $8.0 \mathrm{~cm}$ ), antimongoloid slanting of the palpebral fissures, wide anterior fontanelle and metopic suture, posteriorly rotated ears, bilateral cleft lip and palate, a systolic ejection murmur, and penoscrotal hypospadias with normal testes and scrotum. Neurological examination was normal apart from mild generalised hypotonia.

Normal investigations included banded karyotype, thyroid function, EEG, CT scan, skeletal survey, and intravenous pyelogram. Radiographical studies of the oesophagus showed slight aspiration above the level of the cricopharyngeus. Laryngoscopy showed a small posterior laryngeal cleft. A patent ductus arteriosus was found at cardiac catheterisation and angiography as well as a secundum type atrial septal defect, mild aortic

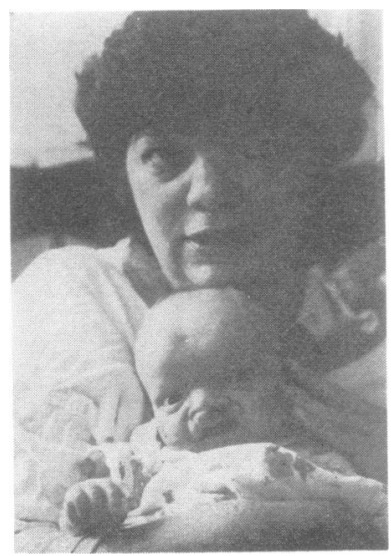

FIGURE The proband aged 6 weeks with his mother. coarctation, and a persistent left superior vena cava draining into the coronary sinus.

The baby responded well to digitalisation but required tracheostomy at the age of 8 weeks because of recurrent chest infection associated with recurrent aspiration.

The infant's parents are unrelated. His mother (figure) shows hypertelorism and a widow's peak, with inner canthal distance $4.0 \mathrm{~cm}$, interpupillary distance $7.0 \mathrm{~cm}$, and outer canthal distance $10.5 \mathrm{~cm}$. She is in good general health and has had no serious illnesses with no history of stridor in infancy. Three previous pregnancies resulted in one healthy male and two first trimester miscarriages. A maternal aunt has marginal hypertelorism with a widow's peak. The infant's father is healthy with no congenital abnormalities. Family photographs show no evidence of hypertelorism or telecanthus in other family members including materna grandparents.

The differential diagnosis in this infant and his mother rests between the $G$ (Opitz-Frias) and BBB (Opitz) syndromes with the presence of a laryngeal cleft strongly favouring the former. ${ }^{2}$ The major midline defects in the proband fall at the severe end of the spectrum of the $G$ syndrome, in which cardiovascular anomalies are unusual. In one patient a ventricular septal defect, patent ductus arteriosus, and pulmonary hypertension were demonstrated at catheterisation, ${ }^{2}$ and in another the heart was found at necropsy to lie in the midline and to have abnormal venous drainage. ${ }^{3}$ The features in the present case graphically illustrate the remarkable intrafamilial variation which can occur in this disorder.

I D YounG Department of Genetics, The Hospital for Sick Children, 555 University Avenue, Toronto, Ontario, Canada.

References

1 Funderburk SJ, Stewart R. The $\mathrm{G}$ and BBB syndromes: case presentations, genetics and nosology. Am J Med Genet 1978:2:131-44.

2 Cordero JF, Holmes LB. Phenotypic overlap of the BBB and $\mathrm{G}$ syndromes. Am J Med Genet 1978;2:145-52.

${ }^{3}$ Gilbert EF, Viseskul V, Mossman HW, Opitz JM. The pathologic anatomy of the $\mathrm{G}$ syndrome. $Z$ Kinderheilkd 1972;111:290-8.

Requests for reprints to Dr I D Young, Department of Child Health, Clinical Sciences Building, Leicester Royal Infirmary, PO Box 65, Leicester LE2 7LX. 